\title{
Effect of Cold-Mediated Pretreatment on Microspore Culture in Winter and Spring Wheat
}

\author{
Rituraj Khound $^{1}$, Meenakshi Santra ${ }^{2}$, P. Stephen Baenziger ${ }^{3}$, Dipak K. Santra ${ }^{{ }^{*}}$ \\ ${ }^{1}$ Panhandle Research and Extension Center, University of Nebraska-Lincoln, Scottsbluff, USA; ${ }^{2}$ Soil and Crop Sciences, Colorado \\ State University, Fort Collins, USA; ${ }^{3}$ Department of Agronomy and Horticulture, University of Nebraska-Lincoln, Lincoln, USA. \\ Email: *dsantra2@unl.edu
}

Received September 29 $9^{\text {th }}, 2013$; revised October $20^{\text {th }}, 2013$; accepted October $29^{\text {th }}, 2013$

Copyright (C) 2013 Rituraj Khound et al. This is an open access article distributed under the Creative Commons Attribution License, which permits unrestricted use, distribution, and reproduction in any medium, provided the original work is properly cited.

\begin{abstract}
Microspore culture of wheat generates completely homozygous (doubled haploid) plants in a single generation thereby reducing the time required for wheat variety development. Success of microspore culture in spring wheat is relatively higher than that in winter wheat. Cold mediated pretreatment was reported to improve response of microspore culture in wheat. The objective of the study was to determine and compare the influence of cold pretreatment on microspore culture in spring and winter wheat. Three spring ("Chris", "Express", and "Macon") and three winter ("Anton", "Antelope", and "Camelot") wheat cultivars were used. In cold pretreatment, excised anthers were incubated in solution B at $25^{\circ} \mathrm{C}-28^{\circ} \mathrm{C}$ for $4-5$ days followed by cold treatment at $4^{\circ} \mathrm{C}$ for 5 days and were compared with the no-cold pretreatment at $25^{\circ} \mathrm{C}-28^{\circ} \mathrm{C}$ for $4-5$ days. Isolated microspores were cultured in induction medium (MMS4) at $27^{\circ} \mathrm{C}-28^{\circ} \mathrm{C}$ for 25 - 30 days in the dark. Embryos (1 - $2 \mathrm{~mm}$ size) were transferred to regeneration medium (MMS5). Numbers of multicellular structures, transferable embryos and green plants were counted and data were used for analysis of variance using a generalized linear model. It was observed that cold pretreatment increased multicellular structures, transferable embryos and green plants in both spring and winter wheat. However, the degree of improvement was higher in spring wheat compared to winter wheat. The cultivars within spring and winter wheat responded differently. Development of embryos from pro-embryos was $4-5$ folds lower in winter wheat than that in spring wheat, indicating requirement of a possibly different hormonal composition in induction medium for improving embryo induction in winter wheat. This report may provide future direction of research to improve microspore culture response in winter wheat.
\end{abstract}

Keywords: Androgenesis; Doubled Haploid; Homozygosity; Biotechnology; Breeding

\section{Introduction}

Microspore culture is a tissue culture based on the method to produce completely homozygous (doubled haploid; DH) plants from immature pollen grains. Single seed descent (SSD) method is usually used for generating homozygous lines in wheat (Triticum aestivum L.) breeding. However, six generations of inbreeding are required to obtain $98 \%$ homozygosity in SSD method. Microspore culture generates $100 \%$ homozygous lines within one generation which saves time, space and labor [1]. Since winter wheat requires 6 to 8 weeks of vernalization to induce flowering in every generation, microspore culture can possibly increase the efficiency of breeding programs. Besides breeding programs, DH plants have also been

${ }^{*}$ Corresponding author. used in plant transformation [2], gene mapping [3] and mutation studies [4].

There are two basic methods of and cogenesis for production of DH plants viz., 1) anther and 2) isolated microspore culture. In isolated microspore culture, microspores are isolated from anthers prior to culture, whereas anther culture involves culturing the whole anthers [5]. Microspore culture comprises three steps: pretreatment, induction and regeneration. During pretreatment, microspores are subjected to different stresses which switch them from gametophytic to sporophytic development. Carbohydrate starvation using cold shock [6] and heat shock [7] are the most commonly used pretreatment methods. During pretreatment, microspores are induced into the embryogenic stage characterized by a star-like appearance, resulting from a fragmented vacuole and peri- 
pheral cytoplasmic pocket containing the nucleus. For pretreatment, both anthers and spikes are used as explants. Induction is the process of developing embryos from embryogenic microspores. Regeneration involves germination of microspore derived embryos, followed by development of shoots and roots.

Success in microspore culture depends on several factors such as health and genotype of donor plants, conditions during plant growth, pretreatment method, composition of induction and regeneration media, and density of microspores in the induction medium [8,9]. Isolated microspore culture derived wheat plant was first reported by Mejza et al. (1993) [10] and Tuvesson and Ohlund (1993) [11]. Since then, several methods to improve the efficiency of embryo production from isolated microspores have been published [5,6,12-14].

There are several reports of successful androgenesis from pretreated anthers in wheat [14-18]. In these reports, anther pretreatment temperature was in the range of $25^{\circ} \mathrm{C}$ - $33^{\circ} \mathrm{C}$. The success was somewhat limited due to setbacks like low embryo formation rate [15] and high rate of albinism [17]. Cold pretreatment at $4^{\circ} \mathrm{C}$ for several days was reported to have a beneficial effect on androgenic response and spontaneous chromosome doubling in wheat $[1,8,16]$. Pretreatment at cold reportedly delayed the mitotic division of the nucleus, thereby synchronizing the stage of all the microspores during pretreatment resulting in higher induction frequencies [16]. Moreover, low temperature was speculated to increase the ratio of green to albino plants [13].

Several spring wheat cultivars were found to be highly responsive to microspore culture $[14,19]$. On the other hand, winter wheat was observed to be less responsive compared to spring wheat [17]. There are fewer reports of cold temperature effect during pretreatment on microspore culture in winter wheat compared to spring wheat. Comparative analysis of microspore culture response to cold and no cold pretreatments in spring and winter wheat may provide some clue for future investigation to improve response in winter wheat. However, no such comparative analysis has been reported. Therefore, it is imperative to learn if cold pretreatment can effectively improve androgenesis in both spring and winter wheat. The objectives of this study were to assess: 1) the effect of cold pretreatment on microspore culture in spring and winter wheat, and 2) the influence of genotype of wheat on the success of microspore culture.

\section{Materials and Methods}

\subsection{Plant Material and Growth Conditions}

Three spring wheat cultivars viz. Macon [20], Chris [21] and Express [22] and three winter wheat cultivars viz. Antelope [23], Anton [24] and Camelot [25] were used as donor plant material for this study. The plants were grown in a greenhouse maintained at $20^{\circ} \mathrm{C}-23^{\circ} \mathrm{C}$ day $/ 14^{\circ} \mathrm{C}-16^{\circ} \mathrm{C}$ night temperatures with $18 \mathrm{~h}$ day $/ 6 \mathrm{~h}$ night photoperiod regime. The plants were watered every al- ternate day and fertilized every week with 20:20:20 NPK water soluble fertilizer.

\subsection{Pretreatment}

The spikes were harvested at half-opened stage when majority of the anthers contained mostly mid to late uninucleated stage microspores [6]. Each experiment consisted of 1100 - 1200 anthers, which were dissected from approximately 12 - 15 spikes and each experiment was replicated three times. Two types of pretreatment methods were employed viz., no-cold and cold. For no-cold pretreatment, the anthers were aseptically removed from the surface sterilized spikes and placed in $4 \mathrm{ml}$ solution B [7] in $60 \mathrm{~mm} \times 15 \mathrm{~mm}$ sterile petri dishes. Then the anthers were incubated at $25^{\circ} \mathrm{C}-28^{\circ} \mathrm{C}$ for $4-5$ days in dark [26]. In case of cold treatment method, the anthers were transferred to $4^{\circ} \mathrm{C}$ for additional 5 days after $4-5$ days at $25^{\circ} \mathrm{C}-28^{\circ} \mathrm{C}$.

\subsection{Microspore Isolation and Induction}

Isolation of microspores from pretreated anthers was performed as described by Indrianto et al. (1999) [7] with few modifications. The pretreated anthers were transferred to $50 \mathrm{ml}$ tubes and vortexed for 5 minutes. The suspended solution of microspores was sieved through $90 \mu$ mesh and microspores were collected as a pellet after centrifugation at $800 \mathrm{~g}$ for 5 minutes. Isolated embryogenic microspores were collected from the suspended pellet by a density gradient centrifugation technique using $21 \%$ maltose [6]. The isolated microspores were co-cultured in $2-4 \mathrm{ml}$ MMS4 induction medium with $5-7$ wheat ovaries in a $60 \mathrm{~mm} \times 15 \mathrm{~mm}$ petri plate, followed by incubation at $27^{\circ} \mathrm{C}-28^{\circ} \mathrm{C}$ for $25-30$ days in dark. Plates were inspected weekly for loss of media owing to evaporation, and $0.2-0.5 \mathrm{ml}$ fresh medium was added as needed. Brown ovaries were replaced with fresh ovaries whenever required.

\subsection{Regeneration}

After 3 - 4 weeks in induction medium, microspore derived embryos were transferred aseptically to MMS5 regeneration medium [6]. Embryos (1 - $2 \mathrm{~mm}$ in size) were transferred with a sterile forceps from induction medium into solid regeneration medium in $90 \mathrm{~mm}$ plates and incubated in dark for $3-4$ days. Then the embryos were transferred to full light growth chamber at $24^{\circ} \mathrm{C}(16$ $\mathrm{h}$ day and $8 \mathrm{~h}$ dark). After two weeks, regenerated green plants were transferred to magenta boxes containing Murashige and Skoog solid media without plant hor- 
mones and incubated at $24^{\circ} \mathrm{C}$ with $16 \mathrm{~h}$ day $/ 8 \mathrm{~h}$ night photoperiod until they reached the 4 - 5 leaves stage.

\subsection{Data Recording and Statistical Analysis}

After two weeks of culturing the embryogenic cells in induction medium, number of multicellular structures (MCS), also known as pro-embryos, was counted using an inverted microscope and an average was taken from three replications. Numbers of transferrable embryos (TE) and green plants (GP) were also counted visually after 3 4 and 6 weeks, respectively. The data were transformed to stabilize the variance effectively [27] where embryos without plant production were assigned a value of zero and data were transformed by $\sqrt{(\mathrm{X}+1)}$. Data were analyzed using a generalized linear model analysis of variance [28]. Least significant difference (LSD) was used to separate significantly different means.

\section{Results}

\subsection{Differential Effect in Spring and Winter Wheat}

Spring and winter wheat responded differently to microspore culture when cold and no cold pretreatments were used (Table 1). When MCS was compared between cold pretreated spring and winter wheat, it was observed that cold-mediated pretreatment produced higher number of MCS in winter wheat (44.26) than that in spring (34.43) but the difference was non-significant. Similarly, MCS was higher in winter wheat after no-cold pretreatment compared to spring wheat and the difference was significant. However, the TE and GP were significantly higher in spring wheat (13.76 and 7.64, respectively) than that in winter wheat (2.85 and 1.39 , respectively) after cold pretreatment. Significantly higher TE and GP were also observed in spring wheat compared to winter wheat in case of no cold pretreatment. When compared with no cold pretreatment, cold pretreatment increased MCS, TE, and GP from 22.75 to 34.43 (51\% increase), 6.90 to $13.76(99 \%)$, and 3.80 to $7.64(101 \%)$, respectively in spring wheat. Similar results were also obtained in winter wheat but the degree of multiplication was less. Cold pretreatment increased MCS, TE, and GP from 32.56 to $44.26(36 \%), 2.14$ to 2.85 (3\%) and 1.09 to 1.39 $(3 \%)$, respectively in winter wheat.

Green plant recovery was significantly lower in winter wheat than in spring wheat although MCS yield was higher in former than later irrespective of the pretreatment methods. To understand this, developmental progress was compared in both spring and winter wheat under both pretreatment conditions (Table 2). Under cold pretreatment, $39 \%$ of MCS developed into TE in spring wheat, whereas it was 7\% in winter wheat. Under no cold pretreatment, $31 \%$ of MCS developed into TE in spring
Table 1. Microspore culture response of spring and winter wheat on multicellular structure (MCS), transferable embryos (TE) and green plants (GP) under cold and no cold pretreatments.

\begin{tabular}{ccccccc}
\hline \multirow{2}{*}{$\begin{array}{c}\text { Treatments } \\
\text { (growth } \\
\text { habit type) }\end{array}$} & \multicolumn{2}{c}{$\begin{array}{c}\text { Mean value of trait after } \\
\text { cold pretreatment }\end{array}$} & \multicolumn{3}{c}{$\begin{array}{c}\text { Mean value of trait after } \\
\text { no cold pretreatment }\end{array}$} \\
\cline { 2 - 7 } & $\mathbf{M C S}^{\mathbf{a}}$ & $\mathbf{T E}^{\mathbf{b}}$ & $\mathbf{G P}^{\mathbf{c}}$ & $\mathbf{M C S}^{\mathbf{a}}$ & $\mathbf{T E}^{\mathbf{b}}$ & $\mathbf{G P}^{\mathbf{c}}$ \\
\hline Spring & $34.43 \mathrm{~A}^{\#}$ & $13.76 \mathrm{~A}$ & $7.64 \mathrm{~A}$ & $22.75 \mathrm{~B}$ & $6.90 \mathrm{~A}$ & $3.80 \mathrm{~A}$ \\
Winter & $44.26 \mathrm{~A}$ & $2.85 \mathrm{~B}$ & $1.39 \mathrm{~B}$ & $32.56 \mathrm{~A}$ & $2.14 \mathrm{~B}$ & $1.09 \mathrm{~B}$ \\
LSD (0.05) & 11.23 & 3.35 & 2.06 & 11.11 & 0.81 & 0.39 \\
\hline
\end{tabular}

$\bar{a}=$ Multicellular structure counted after 2 weeks. $^{b}=$ Transferable embryos counted after 3 - 4 weeks. ${ }^{c}=$ Green plants counted after 6 weeks. ${ }^{\#}=$ Numbers followed by the same letter are not significantly different at 0.05 level.

Table 2. Microspore culture response as measured by rate of conversion of multicellular structure (MCS) into transferable embryos (TE), transferable embryos (TE) into green plants and multicellular structure (MCS) into green plants (GP) in spring and winter wheat under cold and no cold pretreatments.

\begin{tabular}{ccccccc}
\hline \multirow{2}{*}{$\begin{array}{c}\text { Treatments } \\
\text { (growth } \\
\text { habit type) }\end{array}$} & \multicolumn{3}{c}{$\begin{array}{c}\text { \% conversion after cold } \\
\text { pretreatment }\end{array}$} & $\begin{array}{c}\text { \% conversion after no } \\
\text { cold pretreatment }\end{array}$ \\
\cline { 2 - 7 } & MCS to & $\begin{array}{c}\text { MCS to } \\
\text { TE }\end{array}$ & $\begin{array}{c}\text { TE to } \\
\text { GP }\end{array}$ & $\begin{array}{c}\text { MCS to } \\
\text { TE }\end{array}$ & $\begin{array}{c}\text { MCS to } \\
\text { GP }\end{array}$ & $\begin{array}{c}\text { TE to } \\
\text { GP }\end{array}$ \\
\hline Spring & $39 \mathrm{~A}^{\#}$ & $22 \mathrm{~A}$ & $56 \mathrm{~A}$ & $31 \mathrm{~A}$ & $18 \mathrm{~A}$ & $62 \mathrm{~A}$ \\
Winter & $7 \mathrm{~B}$ & $4 \mathrm{~B}$ & $57 \mathrm{~A}$ & $8 \mathrm{~B}$ & $4 \mathrm{~B}$ & $56 \mathrm{~A}$ \\
LSD (0.05) & 7 & 3 & 17 & 3 & 4 & 25 \\
\hline
\end{tabular}

wheat, while it was $8 \%$ in winter wheat. Therefore, conversion of MCS into TE was significantly (4 - 5 folds) lower in winter wheat than that in spring wheat under both cold and no cold pretreatments. However, that was not true in case of TE into GP. Conversion of TE into GP was similar in both spring (56\%) and winter (57\%) wheat under cold pretreatment. It was also similar under no cold pretreatment in both spring $(62 \%)$ and winter $(56 \%)$ wheat.

\subsection{Genotype Effect}

Differential responses to microspore culture were observed among all the spring and winter wheat cultivars (Table 3). After both cold and no cold pretreatments, MCS in all the three spring cultivars were not significantly different. Macon had the lowest MCS (25.58) among the three spring wheat cultivars after cold pretreatment. Under cold pretreatment, the difference in TE in Macon was significantly lower than Chris and Express, which had similar TE. However, TE was non-significant among the three spring cultivars in case of no cold pretreatment. Significant difference was observed among the cultivars in GP. In both cold and no cold pretreatments, Chris generated highest GP and was significantly higher than Macon and Express. In case of winter wheat, 
Table 3. Microspore culture response of three spring and three winter wheat cultivars on multicellular structure (MCS), transferable embryos (TE) and green plants (GP) in spring and winter wheat under two pretreatment methods.

\begin{tabular}{ccccccc}
\hline \multirow{2}{*}{$\begin{array}{c}\text { Treatments } \\
\text { (Variety) }\end{array}$} & \multicolumn{3}{c}{$\begin{array}{c}\text { Mean value of trait after } \\
\text { cold pretreatment }\end{array}$} & \multicolumn{3}{c}{$\begin{array}{c}\text { Mean value of trait } \\
\text { (NC) }\end{array}$} \\
\cline { 2 - 7 } & $\mathbf{M C S}^{\mathbf{a}}$ & $\mathbf{T E}^{\mathbf{b}}$ & $\mathbf{G P}^{\mathbf{c}}$ & $\mathbf{M C S}^{\mathbf{a}}$ & $\mathbf{T E}^{\mathbf{b}}$ & $\mathbf{G P}^{\mathbf{c}}$ \\
\hline Macon (spring) & $25.58 \mathrm{~B}$ & $7.870 \mathrm{~B}$ & $4.90 \mathrm{C}$ & $19.30 \mathrm{C}$ & $7.50 \mathrm{~A}$ & $3.60 \mathrm{~B}$ \\
$\begin{array}{c}\text { Chris (spring) } \\
\begin{array}{c}\text { Express } \\
\text { (spring) }\end{array}\end{array}$ & $42.45 \mathrm{AB}^{\#}$ & $17.83 \mathrm{~A}$ & $10.75 \mathrm{~A}$ & $25.50 \mathrm{BC}$ & $6.70 \mathrm{~A}$ & $4.35 \mathrm{~A}$ \\
$\begin{array}{c}\text { Antelope } \\
\text { (winter) }\end{array}$ & $26.33 \mathrm{~B}$ & $1.71 \mathrm{C}$ & $1.26 \mathrm{D}$ & $16.64 \mathrm{C}$ & $2.06 \mathrm{~B}$ & $1.14 \mathrm{C}$ \\
$\begin{array}{c}\text { Anton (winter) } \\
\begin{array}{c}\text { Camelot } \\
\text { (winter) }\end{array}\end{array}$ & $53.33 \mathrm{~A}$ & $2.63 \mathrm{C}$ & $1.79 \mathrm{D}$ & $33.14 \mathrm{~B}$ & $1.66 \mathrm{~B}$ & $1.14 \mathrm{C}$ \\
\hline
\end{tabular}

${ }^{a}=$ Multicellular structure counted after 2 weeks. ${ }^{b}=$ Transferable embryos counted after 3 - 4 weeks. ${ }^{c}=$ Green plants counted after 6 weeks. ${ }^{\#}=$ Numbers followed by the same letter are not significantly different at 0.05 level.

MCS in Antelope were significantly lower than Anton and Camelot for cold and no cold pretreatments. Moreover, MCS in Camelot was significantly higher than that of Anton after no cold pretreatment. Surprisingly, no significant difference was observed among the three winter wheat cultivars in terms of TE and GP after both pretreatments.

\section{Discussion}

Effect of cold on microspore culture response was different in various reports. Cold pretreatment was observed to have negative effects on microspore induction in hexaploid wheat but positive effect on plant regeneration in durum wheat (T. durum L.) [29]. In other reports, cold pretreatment was found to have neither positive nor adverse effects on microspore embryogenesis [8]. In current report, cold was found to increase MCS, TE and GP. However, degree of improvement was better in spring wheat than winter wheat. Although cold pretreatment increased GP production compared to no cold pretreatment, the improvement was not significant. In general, stress during pretreatment induces recombination of nuclear genes or chloroplast genome, which results in low regeneration, albino plants and somaclonal variation [18]. However, cold pretreatment was found to improve the green plants to albino ratio in our study (data not shown) as suggested by Liu et al. (2002) [13].

Spring wheat in general showed significantly better response to microspore culture than winter wheat similar to earlier report by Tuvesson and Ohlund (1993) [11]. Although they observed good induction in the cultivars of both spring and winter wheat, the multicellular structures in winter wheat cultivars did not develop further. On the other hand, they successfully regenerated green plants from the spring wheat cultivars. We also found similar results in winter wheat. There are more reports where spring cultivars showed better response in green plant regeneration than those of winter wheat $[17,18]$. All these findings suggest that spring wheat is superior than winter wheat in terms of response to microspore culture.

The results from comparison between the cultivars in both spring and winter wheat clearly indicate that responses to isolated microspore culture vary among different genotypes. Effect of genotype on microspore embryogenesis was shown in many reports $[8,9,17,18,30]$. In fact, there are certain genotypes which are generally quite recalcitrant in their in vitro response [9]. Tuvesson and Ohlund (1993) [11] reported significantly different green plant regeneration efficiency between two spring cultivars. It is hence apparent that genotypes belonging to even the same growth habit (spring or winter) of wheat show variable responsiveness to microspore culture. Among the three winter wheat cultivars Camelot produced the highest number of multicellular structures. Yet, Camelot's GP was lower than Antelope and Anton. Tuvesson and Ohlund (1993) [11] reported similar results where one of two spring cultivars produced no green plant at all. Non-viable structures were also included during counting of multicellular structures since it was not possible to distinguish non-viable structures from viable ones. These non-viable structures did not proceed in further development to form embryos and consequently regenerated plants. It seems that such non-viable structures were significantly higher in Camelot than in Antelope and Anton.

It was indicated in the results that green plant recovery was significantly lower ( $\sim$-folds) in winter wheat than in spring wheat although yield of multicellular structures (pro-embryos) was higher in former than later. It was also observed that conversion of multicellular structures (pro-embryos) into embryos was significantly (4 - 5 folds) lower in winter wheat than that in spring wheat. Therefore, it seems that in winter wheat, development of embryos from multicellular structures (pro-embryos) was not as efficient as in spring wheat. This may be the reason of low green plant recovery in winter wheat. In microspore culture, hormones play a crucial part in induction and regeneration [31]. The level of endogenous hormones may vary between spring and winter wheat with different growth habits. A common induction medium may not be equally effective for both spring and winter wheat. Levels of endogenous phytohormones in microspore-derived embryos of spring and winter wheat may be different. This may contribute to the significant difference in development of embryos from pro-embryos (multicellular structures) between spring and winter wheat. Similar factors may be the part of the reason for genotypic differences. This indicates that the hormones 
in induction medium may have to be manipulated to improve microspore culture response in winter wheat. Further study is necessary to address this issue.

\section{Conclusion}

Green plant regeneration was improved by use of cold during pretreatment especially in spring wheat. Success of microspore culture was dependent upon growth habit (spring and winter) and genotype of wheat. Changes in hormones in induction medium may be necessary to improve microspore culture response in winter wheat. This is the first report on comparative assessment of microspore culture response in spring and winter wheat.

\section{Acknowledgements}

The project was funded by Nebraska Wheat Board. Contribution from Allison Hazen is acknowledged.

\section{REFERENCES}

[1] L. Cistue and K. J. Kasha, "Gametic Embryogenesis in Triticum: A Study of Some Critical Factors in Haploid (Microspore) Embryogenesis," In: A. Mujib and J. Samaj, Eds., Somatic Embryogenesis, Plant Cell Monograph, Vol. 2, Springer-Verlag, Berlin, Heidelberg, 2005, pp. 321342. http://dx.doi.org/10.1007/7089 031

[2] L. Folling and A. Olesen, "Transformation of Wheat (Triticum aestivum L.) Microspore-Derived Callus and Microspores by Particle Bombardment," Plant Cell Reports, Vol. 20, No. 11, 2002, pp. 1098-1105. http://dx.doi.org/10.1007/s00299-002-0445-0

[3] A. J. Khan, S. Hassan, M. Tariq and T. Khan, "Haploidy Breeding and Mutagenesis for Drought Tolerance in Wheat," Euphytica, Vol. 120, No. 3, 2001, pp. 409-414. http://dx.doi.org/10.1023/A:1017598202368

[4] A. M. Castillo, L. Cistue, M. P. Valles, J. M. Sanz, I. Romagosa and J. L. Molina-Cano, "Efficient Production of Androgenic Doubled-haploid Mutants in Barley by the Application of Sodium Azide to Anther and Microspore Cultures," Plant Cell Reports, Vol. 20, No. 2, 2001, pp. 105-111. http://dx.doi.org/10.1007/s002990000289

[5] A. M. R. Ferrie and K. L. Caswell, "Isolated Microspore Culture Techniques and Recent Progress for Haploid and Doubled Haploid Plant Production," Plant Cell, Tissue, and Organ Culture, Vol. 104, No. 3, 2011, pp. 301-309. http://dx.doi.org/10.1007/s11240-010-9800-y

[6] K. J. Kasha, E. Simion, M. Miner, J. Letarte and T. C. Hu, "Haploid Wheat Isolated Microspore Culture Protocol," In: M. Maluszynski, K. J. Kasha, B. P. Forster and I. Szarejko, Eds., Doubled Haploid Production in Crop Plants, A Manual, Kluwer Academic Publishers, Dordrecht, 2003, pp. 77-81.

[7] A. Indrianto, E. Heberle-Bors and A. Touraev, "Assessment of Various Stresses and Carbohydrates for Their Effects on the Induction of Embryogenesis in Isolated Wheat Microspores," Plant Science, Vol. 143, No. 1,
1999, pp. 71-79.

http://dx.doi.org/10.1016/S0168-9452(99)00022-9

[8] M. Y. Zheng, "Microspore Culture in Wheat (Triticum aestivum)-Doubled Haploid Production via Induced Embryogenesis," Plant Cell, Tissue and Organ Culture, Vol. 73, No. 3, 2003, pp. 213-230.

http://dx.doi.org/10.1023/A:1023076213639

[9] S. K. Datta, "Androgenic Haploids: Factors Controlling Development and Its Application in Crop Improvement," Current Science, Vol. 89, No. 11, 2005, pp. 1870-1878.

[10] S. J. Mejza, V. Morgant, D. E. DiBona and J. R. Wong, "Plant Regeneration from Isolated Microspore of Triticum aestivum," Plant Cell Reports, Vol. 12, No. 3, 1993, pp. 149-153. http://dx.doi.org/10.1007/BF00239096

[11] I. K. D. Tuvesson and R. C. V. Ohlund, "Plant Regeneration through Culture of Isolated Microspores of Triticum aestivum L.," Plant Cell, Tissue and Org Culture, Vol. 34, No. 2, 1993, pp. 163-167. http://dx.doi.org/10.1007/BF00036097

[12] A. Indrianto, I. Barinova, A. Touraev and E. HeberleBors, "Tracking Individual Wheat Microspores in Vitro: Identification of Embryogenic Microspores and Body Axis Formation in the Embryo," Planta, Vol. 212, No. 2, 2001, pp. 163-174. http://dx.doi.org/10.1007/s004250000375

[13] W. Liu, M. Y. Zheng and C. F. Konzak, "Improving Green Plant Production via Isolated Microspore Culture in Bread Wheat (Triticum aestivum L.)," Plant Cell Reports, Vol. 20, No. 9, 2002, pp. 821-824. http://dx.doi.org/10.1007/s00299-001-0408-x

[14] M. Santra, N. Ankrah, D. K. Santra and K. K. Kidwell, "An Improved Wheat Microspore Culture Technique for the Production of Doubled Haploid Plants," Crop Science, Vol. 52, No. 5, 2012, pp. 2314-2320.

http://dx.doi.org/10.2135/cropsci2012.03.0141

[15] T. C. Hu, A. Ziauddin, E. Simion and K. J. Kasha, "Isolated Microspore Culture of Wheat (Triticum aestivum L.) in a Defined Media I. Effects of Pretreatment, Isolation Methods, and Hormones," In Vitro Cellular and Developmental Biology, Vol. 31, 1995, pp. 79-83.

[16] T. Hu and K. J. Kasha. 1999, "A Cytological Study of Pretreatments Used to Improve Isolated Microspore Cultures of Wheat (Triticum aestivum L.) cv. Chris," Genome, Vol. 42, 1999, pp. 432-441.

[17] C. Lantos, S. Paricsi, A. Zofajova, J. Weyen and J. Pauk, "Isolated Microspore Culture of Wheat (Triticum aestivum L.) with Hungarian Cultivars," Acta Biologica Szegediensis, Vol. 50, No. 1-2, 2006, pp. 31-35.

[18] M. E. Shariatpanahi, K. Belogradova, L. Hessamvaziri, E. Heberle-Bors and A. Touraev, "Efficient Embryogenesis and Regeneration in Freshly Isolated and Cultured Wheat (Triticum aestivum L.) Microspores without Stress Pretreatment," Plant Cell Reports, Vol. 25, No. 12, 2006, pp. 1294-1299. http://dx.doi.org/10.1007/s00299-006-0205-7

[19] M. Y. Zheng, Y. Weng, Y. Liu and C. F. Konzak, "The Effect of Ovary-Conditioned Medium on Microspore Embryogenesis in Common Wheat (Triticum aestivum L.)," Plant Cell Reports, Vol. 20, No. 9, 2002, pp. 802-807. http://dx.doi.org/10.1007/s00299-001-0411-2 
[20] K. K. Kidwell, V. L. De Macon, G. B. Shelton, J. W. Burns, B. P. Carter, C. F. Morris, X. M. Chen and N. A. Bosque-Perez, "Registration of Macon Wheat," Crop Science, Vol. 43, No. 4, 2003, p. 1561. http://dx.doi.org/10.2135/cropsci2003.1561

[21] R. E. Heiner and D. R. Johnston, "Registration of Chris wheat," Crop Science, Vol. 7, No. 2, 1967, p. 170. http://dx.doi.org/10.2135/cropsci1967.0011183X0007000 $\underline{20039 x}$

[22] L. A. Mercado, E. Souza and K. D. Kephart, "Origin and Diversity of North American Hard Spring Wheats," Theoretical and Applied Genetics, Vol. 93, No. 4, 1996, pp. 593-599. http://dx.doi.org/10.1007/BF00417953

[23] R. A. Graybosch, C. J. Peterson, P. S. Baenziger, L. A. Nelson, B. B. Beecher, D. B. Baltensperger and J. M. Krall, "Registration of 'Antelope' Hard White Winter Wheat," Crop Science, Vol. 45, No. 4, 2005, pp. 16611662. http://dx.doi.org/10.2135/cropsci2004.0558

[24] R. A. Graybosch, C. J. Peterson, P. S. Baenziger, D. B. Baltensperger, L. A. Nelson, Y. Jin, J. A. Kolmer, B. W. Seabourn and B. Beecher, "Registration of 'Anton' Hard Red Winter Wheat," Journal of Plant Registrations, Vol. 5, No. 3, 2011, p. 339. http://dx.doi.org/10.3198/jpr2010.08.0481crc

[25] P. S. Baenziger, R. A. Graybosch, L. A. Nelson, R. N. Klein, D. B. Baltensperger, L. Xu, S. N. Wegulo, J. E. Watkins, Y. Jin, J. Kolmer, J. H. Hatchett, M. S. Chen and G. Bai, "Registration of 'Camelot' Wheat," Journal of Plant Registrations, Vol. 3, No. 3, 2009, p. 256. http://dx.doi.org/10.3198/jpr2009.05.0256crc

[26] K. J. Kasha, T. C. Hu, R. Oro, E. Simion and Y. S. Shim, "Nuclear Fusion Leads to Chromosome Doubling during Mannitol Pretreatment of Barley (Hordeum vulgare L.) Microspores," Journal of Experimental Botany, Vol. 52, No. 359, 2001, pp. 1227-1238.

http://dx.doi.org/10.1093/jexbot/52.359.1227

[27] G. W. Snedecor and W. G. Cochran, "Statistical Methods," 6th Edition, The Iowa State University Press, Ames, 1967.

[28] “SAS User's Guide," Version 5 Edition, Cary, SAS Institute, 1985.

[29] M. Ghaemi, A. Sarrafi and G. Alibert, "Influence of Genotype, Media Composition, Cold Pretreatment, and Their Interactions on Androgenesis in Durum Wheat (Triticum turgidum)," Cereal Research Communications, Vol. 23, 1995, pp. 215-227.

[30] W. Liu, M. Y. Zheng, E. A. Polle and C. F. Konzak, "Highly Efficient Doubled-Haploid Production in Wheat (Triticum aestivum L.) via Induced Microspore Embryogenesis," Crop Science, Vol. 42, No. 3, 2002, pp. 686-692. http://dx.doi.org/10.2135/cropsci2002.0686

[31] L. Cistue, M. Soriano, A. M. Castillo, M. P. Valles, J. M. Sanz and B. Echavarri, "Production of Doubled Haploids in Durum Wheat (Triticum turgidum L.) through Isolated Microspore Culture," Plant Cell Reports, Vol. 25, No. 4, 2006, pp. 257-264. http://dx.doi.org/10.1007/s00299-005-0047-8 